\title{
Coupled experimental and numerical investigation of structural glass panels with small slenderness subjected to locally introduced axial compression
}

\author{
Danijel Mocibob ${ }^{\mathrm{a}}$, Jan Belis ${ }^{\mathrm{b}, *}$ \\ a Laboratoire de la construction métallique - ICOM, Ecole Polytechnique Fédérale de Lausanne, GC B3 505, Station 18, CH-1015 Lausanne, Switzerland \\ ${ }^{\mathrm{b}}$ Department of Structural Engineering - LMO, Ghent University, Technologiepark-Zwijnaarde 904, B-9052 Ghent, Belgium
}

\section{A R T I C L E I N F O}

\section{Article history:}

Received 24 September 2008

Received in revised form

18 October 2009

Accepted 1 December 2009

Available online $\mathrm{xxxx}$

\section{Keywords:}

Structural glass

Splitting tension

In-plane compressive load

Contact stress

Crack pattern

\begin{abstract}
A B S T R A C T
Primary load-bearing glass constructions are often subjected to relatively important in-plane loads, transferred through so-called point-fixed connections. The according in-plane load introduction, structural resistance and failure mechanisms have been studied abundantly for axial tensile loading cases, but are relatively unknown for axial compression, in particular when buckling of the compressed component cannot occur. Consequently, stress distributions, resistance and failure mechanisms of small glass specimens subjected to locally introduced axial compression are investigated and presented in this contribution using a coupled experimental and numerical approach. The stress distributions and observed fracture patterns demonstrated that the major failure mechanism was splitting tension: the glass fractured due to high tensile stresses following the compressive stresses. However, the maximal principal tensile stresses at the crack origin were significantly lower compared to the axial tensile loading case. In addition, and in contradiction to the tensile loading case, significant maximal principal compressive stresses were found at the crack origin, leading to the conclusion that the axially compressed glass panels failed due to a complex stress state and not simply to tensile stresses, as is generally assumed in glass design.
\end{abstract}

(C) 2009 Elsevier Ltd. All rights reserved.

\section{Introduction}

Load-bearing glass components are becoming relatively wellaccepted in contemporary building design and construction. Being part of the primary or secondary load-bearing building structure, such components can be subjected to significant and various loading types. Apart from loads perpendicular to the glass surface, such as wind, structural glass components (and their connections) will often be subjected to major in-plane loads, including axial tensile and compressive loads. Some typical examples of glass constructions subjected to major in-plane loads are illustrated in Fig. 1.

To transfer loads between structural glass components, it is relatively common to use so-called point-fixed connection devices, which usually require small metal components to be mechanically attached to boreholes in the glass (friction-grip connections are not meant here). From a mechanical analysis point of view, this problem can often be considered as a contact problem of two cylindrical bodies, which has been described by several authors [1-4].

However, when applied to glass structures, the knowledge about the mechanical behaviour of in-plane loaded components varies dramatically depending on whether tensile or compressive loads are considered.
The in-plane tensile loading case has been studied extensively in literature, e.g. in [5-8], and stress distributions, failure loads and crack patterns are relatively well known.

However, reports on point-fixed glass components subjected to axial compression are very limited, not to say nonexistent. The main reason for this is that the mechanical behaviour of compressed glass components is usually governed by stability issues: over the past few years, several authors have demonstrated that buckling problems (flexural buckling, torsional buckling, lateral torsional buckling, plate buckling and shear buckling) are of utmost importance to define the overall load-bearing capacity of structural glass components in general [9-12] and of glass compression members in particular [13-18]. However, additional (and currently missing) knowledge of the load-bearing capacity of structural glass compression members in which no stability problems can occur would be relevant, e.g. in case of glass components with a very limited buckling length or adequate out-of-plane supports.

Consequently, this paper presents a coupled experimental and numerical investigation of small-scaled axially compressed monolithic and laminated glass components in which loads are locally introduced by means of a point-fixed connection device.

\section{Experimental investigation}

Below, an experimental investigation is presented of glass panels subjected to locally introduced axial compressive loads. In
* Corresponding author. Tel.: +32 926454 78; fax: +32 92645838.
E-mail address: jan.belis@UGent.be (J. Belis). 


\section{$A R T C$ CLE IN PRESS}

Table 1

Main test results for specimens subjected to locally introduced in-plane loads.

\begin{tabular}{|c|c|c|c|c|c|}
\hline Specimen name & $\begin{array}{l}\text { First compressive } \\
\text { breakage load } F_{c, b}(\mathrm{kN})\end{array}$ & $\begin{array}{l}\text { Ultimate compressive } \\
\text { failure load } F_{c, u}(\mathrm{kN})\end{array}$ & $\begin{array}{l}\text { Elongation at failure } \delta_{c, u} \\
\text { (compression case) }(\mathrm{mm})\end{array}$ & $\begin{array}{l}\text { First tensile breakage load } \\
F_{t, b}(\mathrm{kN})\end{array}$ & $\begin{array}{l}\text { Ultimate tensile failure } \\
\text { load } F_{t, u}(\mathrm{kN})\end{array}$ \\
\hline $1 \times 6-1$ & 19.12 & 17.64 & 6.97 & 12.00 & 14.25 \\
\hline $1 \times 6-2$ & 16.32 & 18.92 & 5.70 & 13.26 & 15.08 \\
\hline $1 \times 6-3$ & 15.80 & 19.48 & 7.55 & 14.60 & 21.56 \\
\hline $2 \times 6-1$ & 33.68 & 23.20 & 3.74 & 24.56 & 17.96 \\
\hline $2 \times 6-2$ & 30.44 & 28.76 & 2.55 & 20.04 & 18.72 \\
\hline $2 \times 6-3$ & 23.52 & 21.24 & 3.43 & 32.60 & 32.60 \\
\hline $2 \times 8-1$ & 48.88 & 41.24 & 2.44 & 38.92 & 38.92 \\
\hline $2 \times 8-2$ & 46.04 & 36.88 & 3.61 & 39.48 & 39.48 \\
\hline $2 \times 8-3$ & 51.12 & 35.28 & 4.35 & 49.80 & 49.80 \\
\hline
\end{tabular}

a

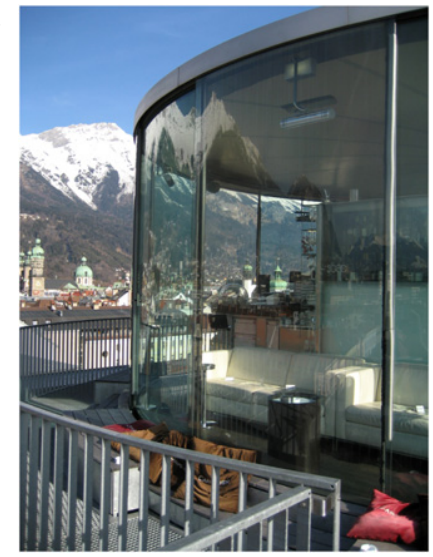

b

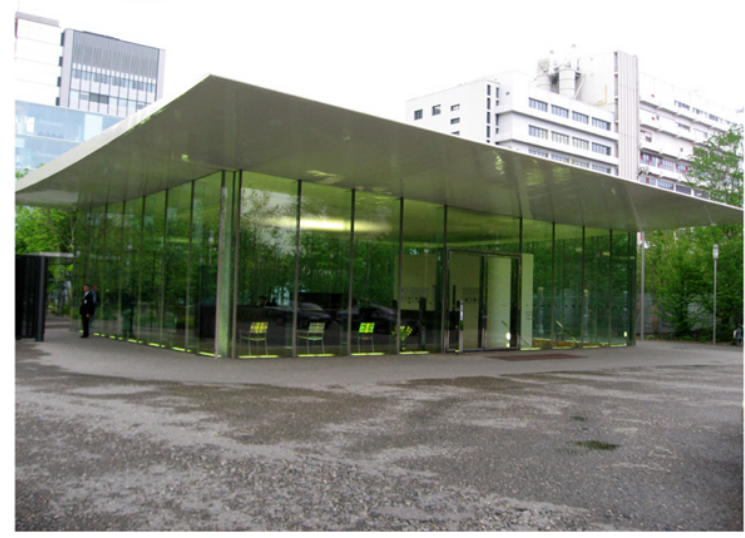

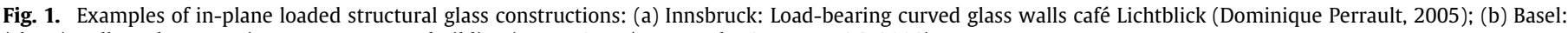
(shear) walls at the Novartis campus entrance building (Marco Serra/Ernst Basler \& Partner AG, 2006).

addition, uniaxial tensile tests have been executed on identical test specimens to allow a comparison of both loading cases.

\subsection{Specimens}

For both loading cases, nine heat-strengthened glass specimens of $200 \mathrm{~mm}$ by $500 \mathrm{~mm}$ have been tested, further divided in three series of three specimens with a different glass thicknesses and/or composition:

$6 \mathrm{~mm}$ monolithic glass $(1 \times 6)$;

$6 \mathrm{~mm}$ glass $/ 1.52 \mathrm{~mm}$ PVB $/ 6 \mathrm{~mm}$ glass laminates $(2 \times 6)$ and

$8 \mathrm{~mm}$ glass $/ 1.52 \mathrm{~mm}$ PVB/ $8 \mathrm{~mm}$ glass laminates $(2 \times 8)$.

The specimen edges and boreholes were polished and chamfered. The slenderness of the test specimens was chosen such that stability problems could not occur. More specifically, to avoid buckling, the specimen length was limited. As the other dimensions, such as the glass thickness, the borehole diameter, etc. had not been rescaled, no significant scale effect was further considered.

Every specimen had been provided with two boreholes $(\varnothing 42 \mathrm{~mm}$ ) in which axially rigid bolted connection devices had been placed to introduce the loads [18]. These connection devices consisted of a steel M20 bolt, a steel tube and a steel cylinder, as illustrated in Fig. 2(c). Between the steel cylinders and the glass a liner material (POM) was placed to avoid direct contact between glass and steel. Subsequently, after the assemblage of the connection devices, Hilti HIT HY 50 mortar [19] was injected in the glass boreholes, filling up the free intermediate space caused by the tolerances of the steel tube and the glass drillings. In doing so, the loads could be introduced to both sheets of the laminated glass specimens in a uniform way, avoiding high local stress concentrations in the glass.

\subsection{Method}

The specimens were subjected to an axial compressive load $\left(F_{c}\right)$ through the load introduction system depicted in Fig. 2. During the displacement controlled tests, the deformations of the glass plates as well as the stress distributions around the borehole and at mid span were measured by linear variable differential transducers (LVDT) and strain gauges respectively.

\subsection{Results and discussion}

The main test results are presented in Table 1, which tables the first breakage load $\left(F_{c, b}\right)$, the failure load $\left(F_{c, u}\right)$ and the corresponding elongation at failure $\left(\delta_{c, u}\right)$ of the specimens subjected to compressive loads. To allow a comparison, the first breakage load $\left(F_{t, b}\right)$ and the ultimate failure load $\left(F_{t, u}\right)$ for the tensile case are tabled as well. In addition, Fig. 3 depicts the relation between the specimens' longitudinal displacements $\left(\delta_{c}\right)$ and the applied in-plane compressive load $\left(F_{c}\right)$.

\subsubsection{Failure mechanisms}

The three test series demonstrated different failure mechanisms.

In the $(1 \times 6)$ specimens, crushing of the mortar due to high compressive loads occurred before breakage of the glass plates. This crushed mortar lead to cracking of the glass due to contrapressure of the steel tube and the glass. However, based on the a posteriori inspection of the tested samples (see Section 2.3.3), it is unlikely that direct contact between glass and steel components took place. Consequently, the specimens demonstrated relatively large, nonlinear displacements and the ultimate glass plate failure did not take place suddenly (Fig. 3(a)). Instead, a progressive failure was observed: after crushing of the mortar and the first breakage 


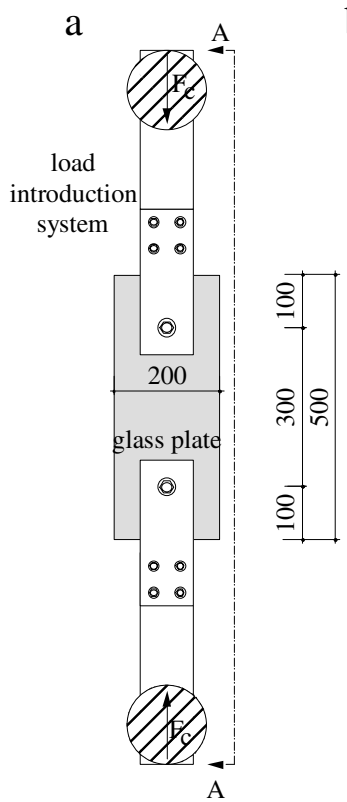

b

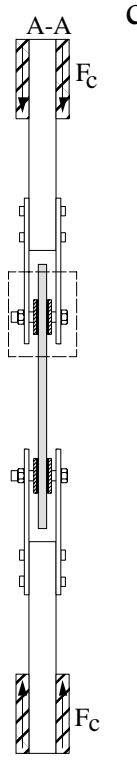

c

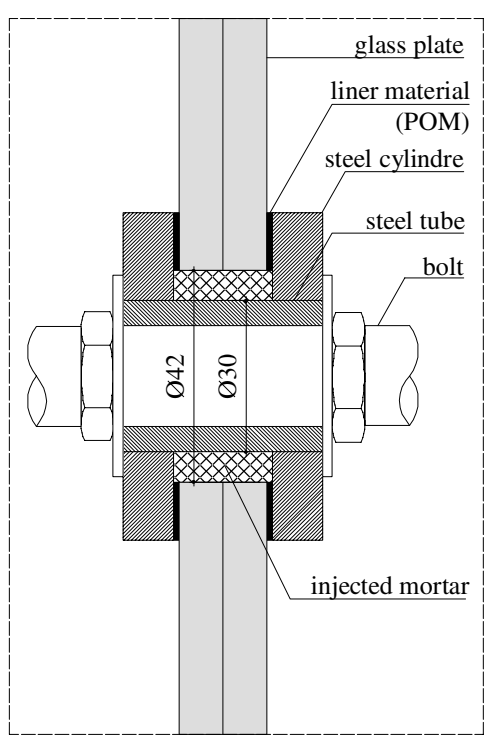

d

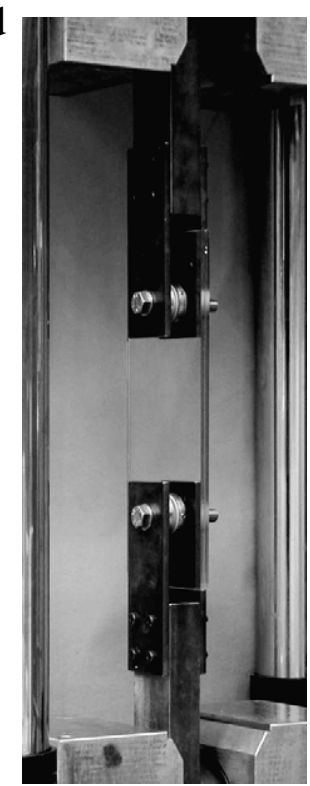

Fig. 2. Glass element under in-plane compressive load: (a) front view; (b) side view; (c) connection detail; (d) test specimen installed in laboratory.

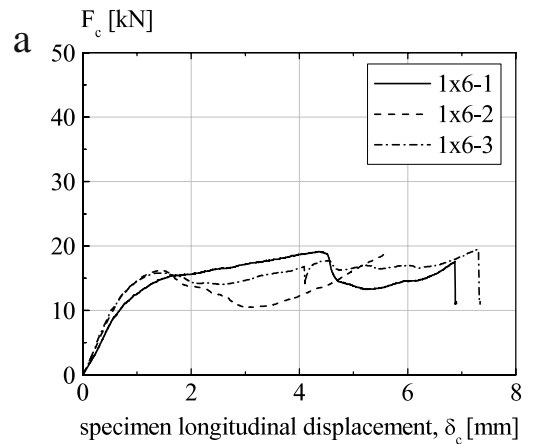

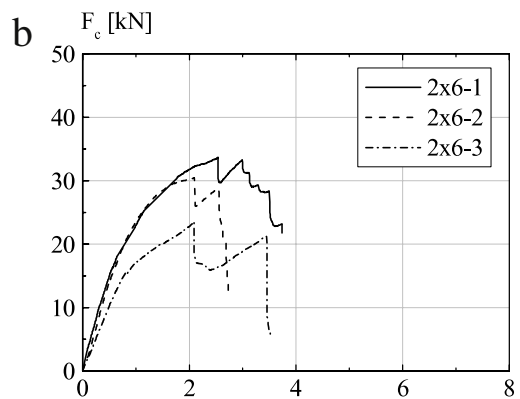

specimen longitudinal displacement, $\delta_{c}[\mathrm{~mm}]$

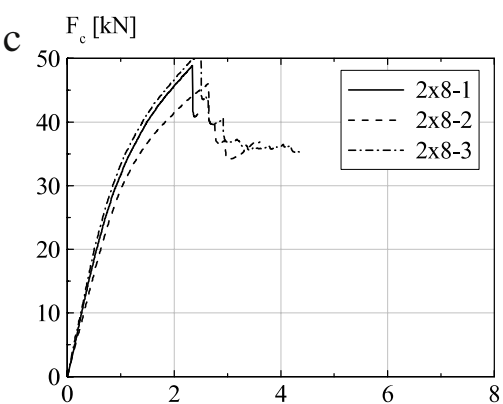

specimen longitudinal displacement, $\delta_{c}[\mathrm{~mm}]$

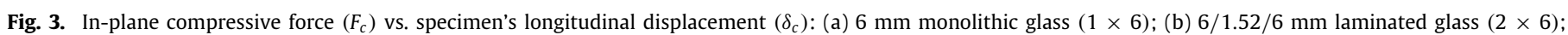
(c) $8 / 1.52 / 8 \mathrm{~mm}$ laminated glass $(2 \times 8)$.

of the glass, the monolithic panel was still able to resist loads comparable to the initial breakage load. Obviously, this residual resistance was only slightly favourable for the specimen's postfailure safety.

Next, the $(2 \times 6)$ specimens demonstrated smaller displacements and higher initial breakage loads (Fig. 3(b)). However, the latter never reached twice the level of the $(1 \times 6)$ failure loads, which might have been expected from the double section area of the $(2 \times 6)$ laminates. On the other hand, both glass sheets failed separately, but at comparable failure loads as illustrated by two local load maxima in Fig. 3(b). Again, the nonlinear loaddisplacement paths are most probably caused by deformation of the injected mortar.

Finally, the highest failure loads and the smallest displacements were observed for the $(2 \times 8)$ specimens (Fig. 3(c)). However, in spite of the significant residual resistance after initial glass breakage, the level of the latter was never reached again.

\subsubsection{Stress analysis}

Ten rosette strain gauges were placed around the glass hole ( $40 \mathrm{~mm}$ from the centre; five at the front and five at the back sides) and two uniaxial strain gauges in the middle of the glass span (one at the front and one at the back side), as indicated in Fig. 4(a).
Subsequently, Fig. 4(b) depicts the distribution of principal tensile stresses $\left(\sigma_{t}\right)$ and principal compressive stresses $\left(\sigma_{c}\right)$ at $40 \mathrm{~mm}$ from the borehole centre (19 $\mathrm{mm}$ from the hole edge). Both maximal principal stresses, tensile and compressive, occurred along the loading axis $\left(\right.$ at $0^{\circ}$ ), but the value of the resulting principal compressive stresses was approximately five times higher compared to the resulting principal tensile stresses. As the absolute value of the stress measurement angles increased, a quick decrease of the maximal principal stresses was observed.

Finally, Fig. 4(c) visualises a comparison of the compressive stresses $\left(\sigma_{c}\right)$ in the middle of the glass specimen, measured with a uniaxial strain gauge $L$, and the nominal compressive stresses $\left(\sigma_{\text {nom }}\right)$, which assume a linear stress distribution at mid span:

$\sigma_{\text {nom }}=\frac{F_{c}}{H \cdot t}$

$F_{c}$ : compressive load $(\mathrm{N})$

$H$ : glass panel width $(\mathrm{mm})$

$t$ : total glass panel thickness $(\mathrm{mm}), t=\sum t_{g}$

$t_{g}$ : individual glass sheet thickness $(\mathrm{mm}), t_{g}=0.976 t_{\mathrm{g}, \text { nom }}$ [9]

$t_{g, \text { nom }}$ : nominal glass sheet thickness $(\mathrm{mm})$.

From the good fit of both linear stress curves, it can be deduced that stress concentrations around the borehole have only a local 


\section{ARTICLE IN PRESS}

a

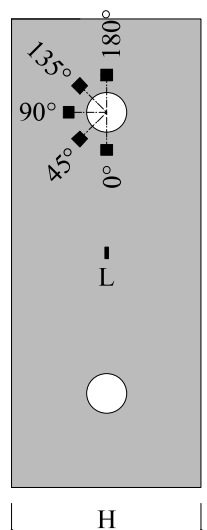

b

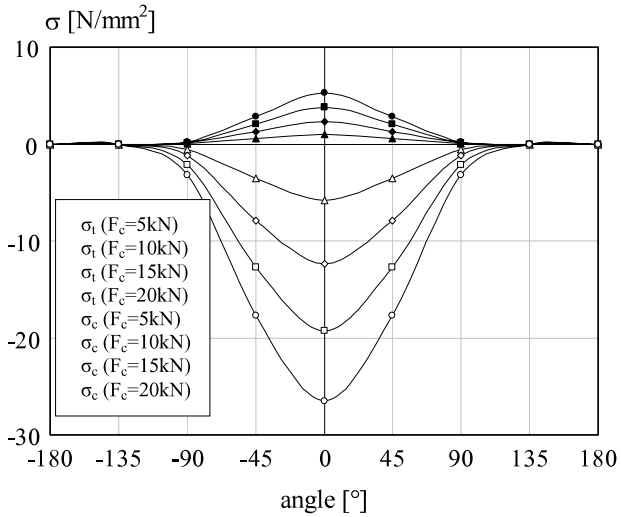

$\mathrm{C} \quad \mathrm{F}_{\mathrm{c}}[\mathrm{kN}]$

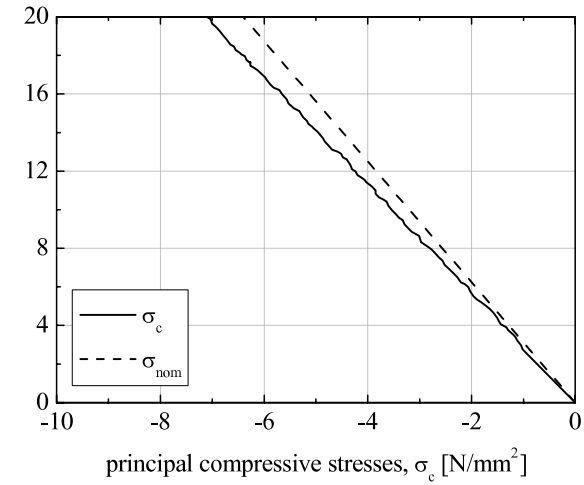

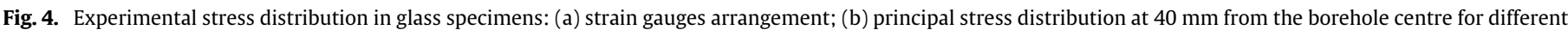
values of $F_{c}$ (black marks present $\sigma_{t}$; white marks present $\sigma_{c}$ ); (c) measured and nominal compressive stresses in the glass at mid-span.
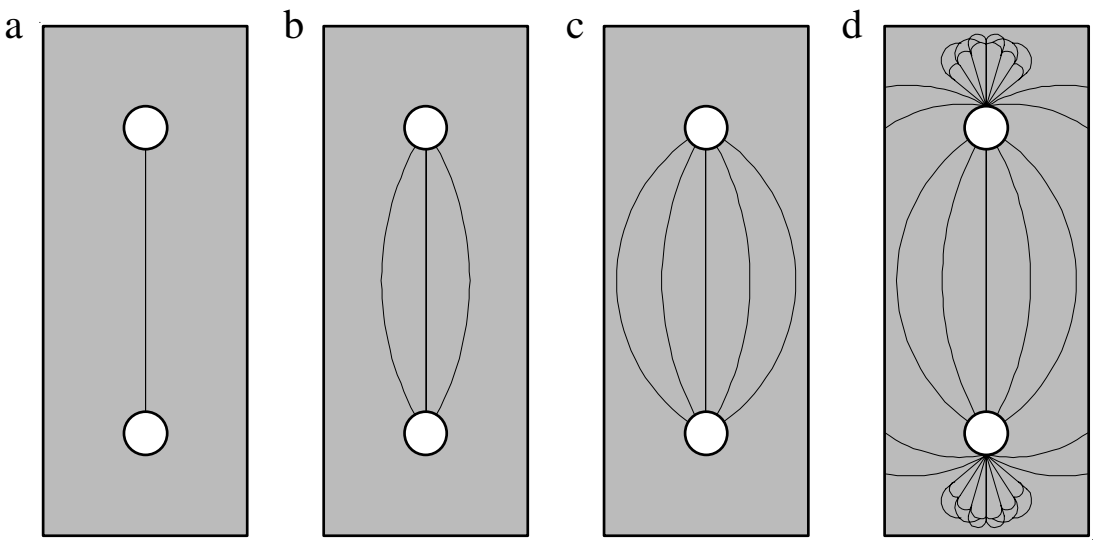

Fig. 5. Schematic overview of splitting tension failure and gradual crack propagation in glass panels subjected to axial compressive loads.

influence, because at a certain distance from the borehole the stress distribution is linear throughout the cross-section.

\subsubsection{Crack patterns}

All test specimens failed progressively during the compressive tests. The first cracks always occurred along the loading axis, between the boreholes (Fig. 5(a)), and propagated in the direction perpendicular to the loading direction. This crack propagation could be explained by indirect tensile stresses. Consequently, the according crack pattern will further be referred to as "splitting tension". At first sight, the observed crack patterns look very similar to the so-called Brazilian test, a frequently applied test on concrete cylinders to evaluate fracture processes due to tensile stresses. However, closer investigation revealed that the glass and concrete cases are very different with respect to crack initiation: in the glass, cracks initiated at the place of maximal principal stresses, i.e. at the contact point $\left(0^{\circ}\right)$, whereas in a Brazilian test, cracks will typically originate from the middle.

Subsequently, as the specimen was still able to carry its load, a second series of cracks occurred, again between both boreholes but in the shape of an arch (Fig. 5(b)). Subsequently, larger crack arches appeared between the boreholes, when the load was further increased (Fig. 5(c)). Finally, when the arches approached the glass edges, cracks in the shape of a fan were observed at the glass boreholes, at $180^{\circ}$ (Fig. 5(d)). In addition, the failed specimen in Fig. 6 illustrates that no direct contact occurred between the steel tube and the glass, in spite of the crushed mortar.
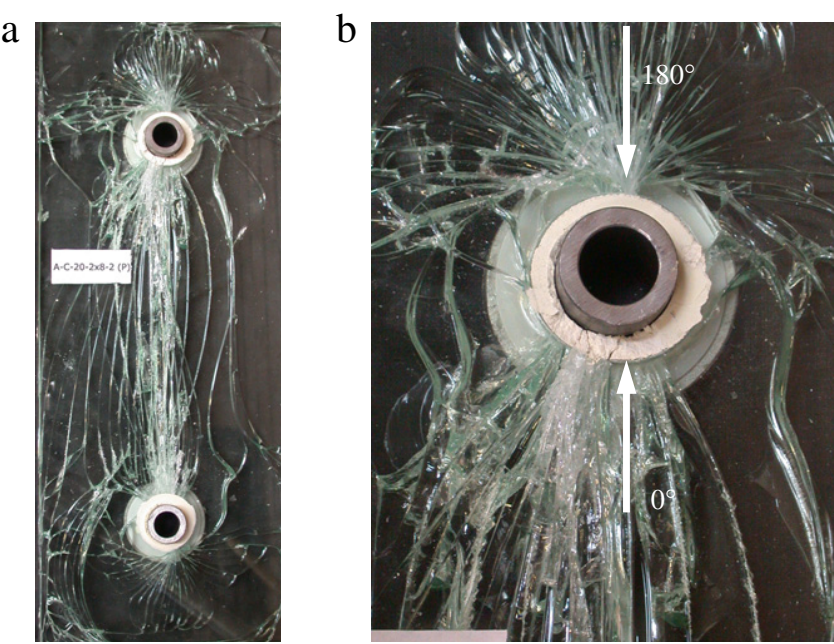

Fig. 6. Experimental splitting tension crack pattern: (a) final crack pattern; (b) detail of crack initiation at the borehole.

Finally, Fig. 6 illustrates the final crack configuration of a glass panel due to in-plane compressive loads. Splitting tension cracks and fan-shaped cracks are visible, respectively between the boreholes and towards the specimen ends (Fig. 6(a)). The position of splitting tension crack initiation is at $0^{\circ}$, while crack initiation of the fan-shape took place at $180^{\circ}$ (Fig. 6(b)). 


\section{Numerical analysis}

\subsection{Numerical model}

Due to symmetry, only the upper half of the tested specimen was numerically modelled using the Finite Element (FE) package Ansys [20]. More possible symmetry planes could have been used, but the computational cost of the model did not necessitate this. The model geometry was identical to the glass panels and connection devices used in the experiments described above. The glass plate (cyan), bolts (yellow) and steel tube (green) were modelled using solid elements, while the injected mortar (red) was simulated using gasket elements, capable of transferring only compressive forces and stresses between adjacent components (Fig. 7) (The gasket elements INTER194 used are 3D elements defined by 16 nodes able to transfer only compressive forces between the meeting components. The deformation of a gasket is restricted to the thickness direction. The element is composed of bottom and top surfaces while the mid-plane is created by averaging the coordinates of node pairs from the bottom and the top). To simulate the contact between the bolts and the steel tube, contact (bolt surface) and target (steel tube surface) elements were used (The used contact elements CONTA 174 and target elements TARGE170 constitute a contact pair. The contact occurs when the element surface penetrates the specified target surface. The CONTA 174 is a 3D surface-to-surface 8-node element while the TARGE170 element is a 3D surfaces element). Subsequently, nonlinear analyses were performed to calculate the effect of a compressive force $\left(F_{c}\right)$ on the model: geometrical and material nonlinearity were introduced by the contact analyses and the elasto-plastic material law used for steel (tube and bolt) respectively.

During the numerical simulations, it is assumed that crushing of the mortar cannot occur. This hypothesis is adopted for the following reasons:

- in the experimental investigation the crushing of the mortar occurred only when monolithic $6 \mathrm{~mm}$ glass specimens were tested. However, in real applications, $6 \mathrm{~mm}$ monolithic glass is never used.

- in the experimental investigation mortar HILTY HIT HY50 was used, with a compressive resistance of $\sigma_{c \text {, mortar }}=50 \mathrm{~N} / \mathrm{mm}^{2}$. Recently on the market, this product was replaced with HILTY HIT HY 70 [21], with equal material properties but with a higher compressive strength $\left(\sigma_{c, \text { mortar }}=70 \mathrm{~N} / \mathrm{mm}^{2}\right)$.

\subsection{Model validation: Comparison of experimental and numerical analysis and validation of the model}

The numerical model was calibrated and validated by comparing the stresses obtained from strain gauge measurements during the experimental investigation to the results obtained with the FE model. Fig. 8 depicts the principal tensile stresses $\left(\sigma_{t}\right)$ at the glass surface at $40 \mathrm{~mm}$ from the borehole centre $(19 \mathrm{~mm}$ from the edge of the borehole, corresponding to the positions where strain gauges had been glued). The continuous line represents the results obtained by the simulation, while the white dots represent the experimental measurements for $F_{c}=20 \mathrm{kN}$. For angles of $0^{\circ}, \pm 45^{\circ}$ and $\pm 135^{\circ}$, the measured results agree very well with the model. On the contrary, the experimental results are somewhat overestimated for an angle of $\pm 90^{\circ}$ and underestimated for an angle of $\left.\pm 180^{\circ}\right)$. The model is calibrated in a way that the highest principal (tensile) stresses at the critical point $\left(0^{\circ}\right)$ correspond to the experimental results. Parameters such as size and friction of the contact surface between bolt and pin as well as mortar material law (modulus of elasticity and nonlinear behaviour) were used in the adoption of the calibration procedure. Consequently, it can be concluded that the numerical model is validated, and that the results are realistic and reasonable.

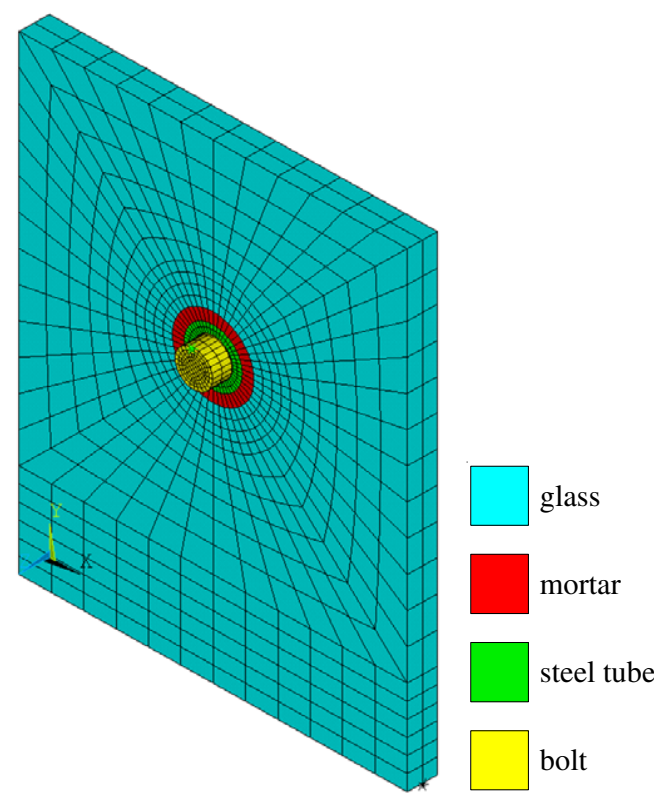

Fig. 7. Numerical model of half a glass panel.

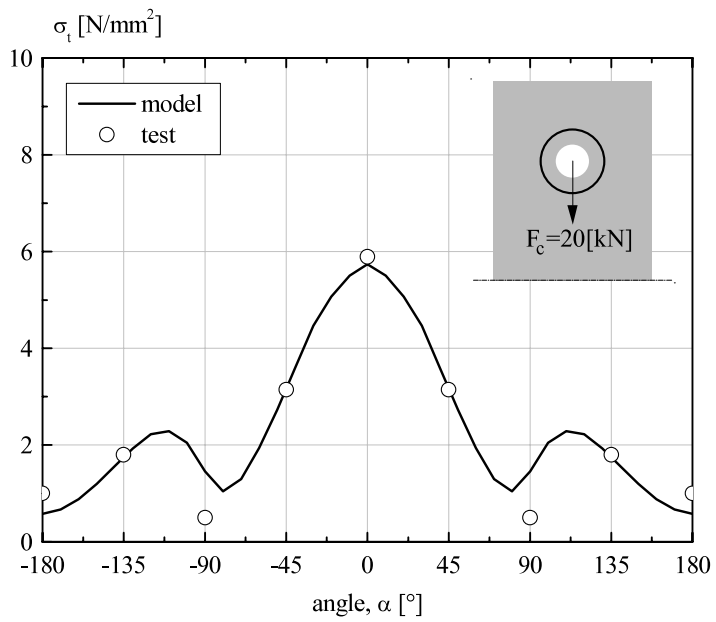

Fig. 8. Comparison between numerical and experimental tensile stresses at $40 \mathrm{~mm}$ from the borehole (compressive loading case, $F_{c}=20 \mathrm{kN}$ ).

\subsection{Results and discussion}

\subsubsection{General stress analysis}

Fig. 9(a) depicts the in-plane deformation of the numerical model subjected to a compressive load introduced through bolts, connection devices and injected mortar to the glass. Consequently, the circular hole was stretched to an oval shape in the loading direction. Fig. 9(b) shows the principal compressive stresses $\left(\sigma_{c}\right)$ while Fig. 9(c) shows the principal tensile stresses $\left(\sigma_{t}\right)$ distribution in the glass panel. As was expected, the maximal principal compressive stresses ( $\sigma_{c, \max }$, blue in Fig. $9(\mathrm{~b})$ ) occurred at the contact area of connection devices and glass panel. At the same time, maximal principal tensile stresses $\left(\sigma_{t, \max }\right.$, red in Fig. 9(c)) in the glass panel occurred at the contact area (at the same place as the maximal principal tensile stresses, as well as at the place of maximal extension of the borehole). However, principal compressive stresses and principal tensile stresses have only a local influence around the glass hole: at a certain distance from the hole, the stresses (colour) are becoming more uniformly distributed. 


\section{ARTICLE IN PRESS}

a

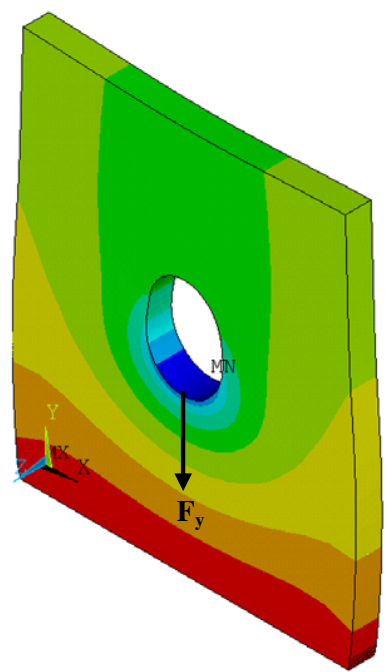

D. Mocibob, J. Belis / Engineering Structures प(III) M-III

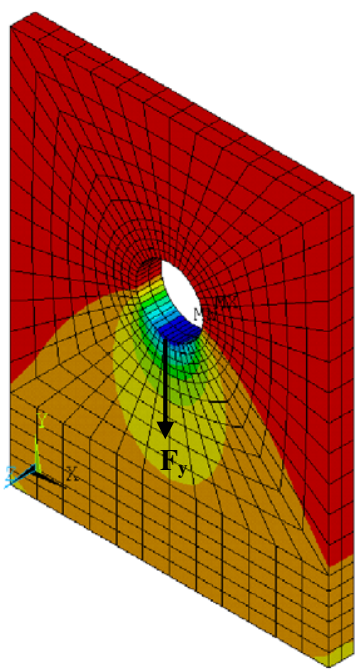

c

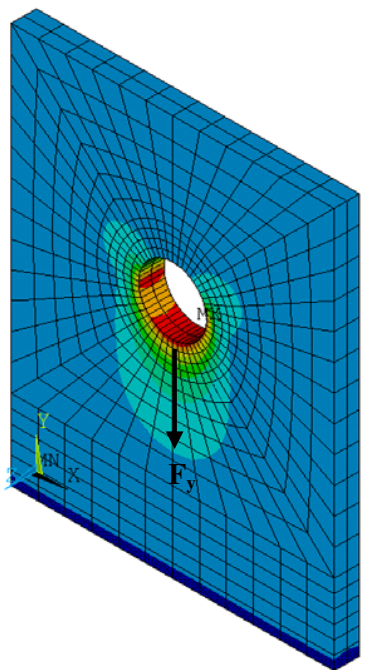

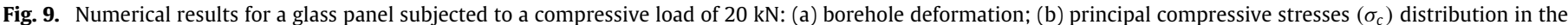
glass panel; (c) principal tensile stresses $\left(\sigma_{t}\right)$ distribution in the glass panel.

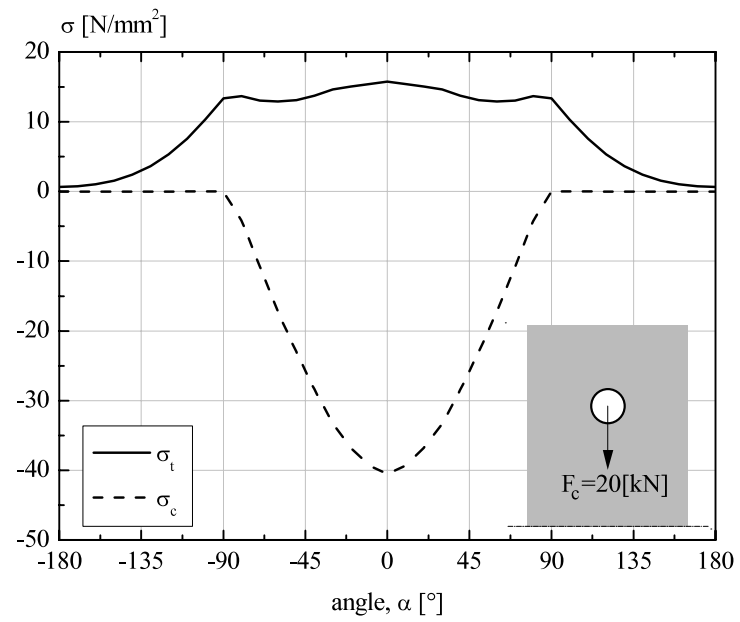

Fig. 10. Principal stresses at the borehole perimeter for a glass specimen subjected to a compressive load.

\subsubsection{Stresses at borehole perimeter}

Principal stress distributions at the borehole perimeter corresponding to a compressive load of $20 \mathrm{kN}$ are presented in Fig. 10.

$$
\sigma_{\mathrm{c}}\left[\mathrm{N} / \mathrm{mm}^{2}\right]
$$

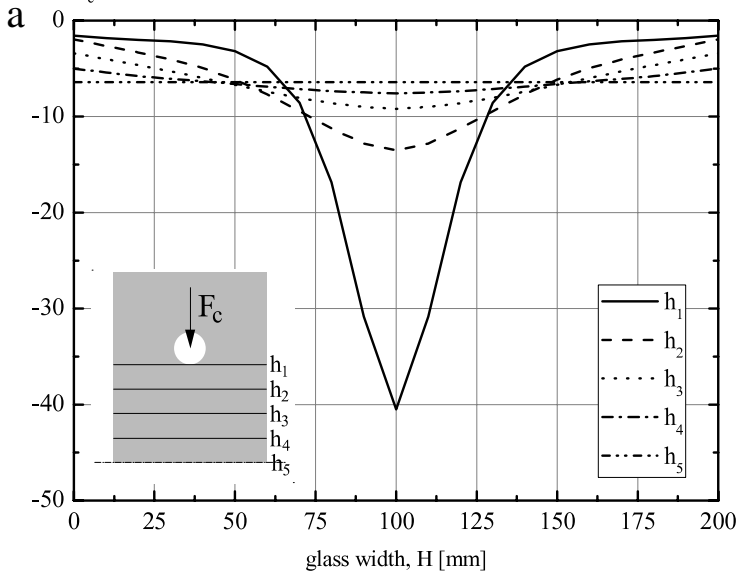

The principal compressive stresses $\left(\sigma_{c}\right)$ are zero for the upper half of the borehole (from $\pm 180^{\circ}$ to $\pm 90^{\circ}$ ) and are increasing in the lower part of the borehole, reaching the absolute maximum at the contact point $\left(0^{\circ}\right)$.

On the other hand, principal tensile stresses $\left(\sigma_{t}\right)$ have an absolute minimum at $\pm 180^{\circ}$ as well, but also three local maxima. The absolute maximum occurs at the contact point $\left(0^{\circ}\right)$, at the same place where the principal compressive stresses $\left(\sigma_{c}\right)$ reach their highest value. The remaining two relative maxima occur at $\pm 90^{\circ}$, at the place where principal compressive stresses start to exceed zero.

\subsubsection{Stresses further away from the borehole}

The principal surface compressive stress distribution along sections perpendicular to the loading direction and at different distances $(h)$ from the borehole is presented in Fig. 11(a).

Along the section tangent to the borehole $\left(h_{1}\right)$ stresses obviously demonstrate a peak at the contact point, but decrease quickly, moving away from the borehole along the same section. Moving to parallel sections further away from the borehole, the stress peak becomes less pronounced, but the stresses near the edges are increasing. Finally, the stress distribution becomes linear at the mid span (section $h_{5}$ ), with a stress level corresponding to the nominal stress value defined in Eq. (1).

$$
\sigma_{t}\left[\mathrm{~N} / \mathrm{mm}^{2}\right]
$$

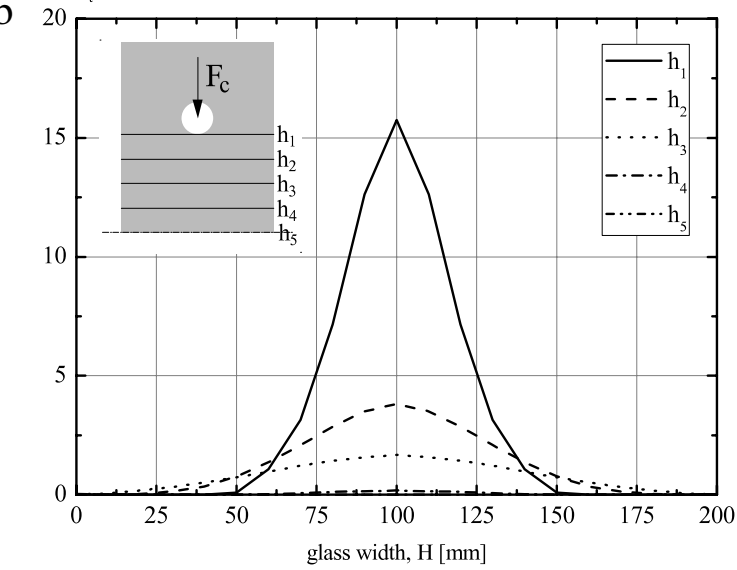

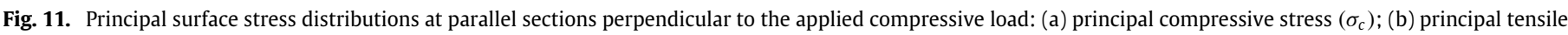
stresses $\left(\sigma_{t}\right)$. 


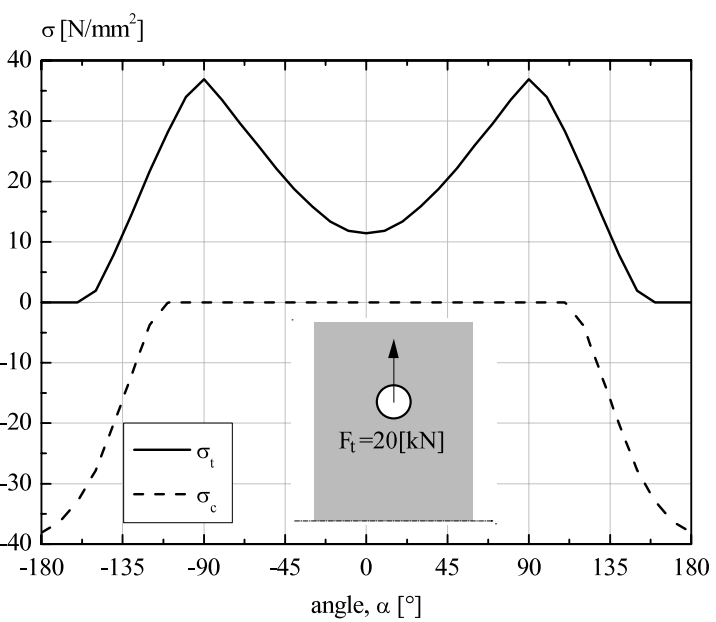

Fig. 12. Principal stresses at the borehole perimeter for a glass specimen subjected to a tensile load of $20 \mathrm{kN}$.

Similarly, Fig. 11(b) depicts the principal tensile stress distribution at the same sections. Again the maximum is observed at the contact point in section $h_{1}$. Moving away from the hole, the stress peak is getting smaller and again disappears completely at section $h_{5}$.

\section{Compressive versus tensile load case: Discussion}

Some remarkable differences can be noticed when the behaviour of glass plates subjected to compressive forces $\left(F_{c}\right)$ is compared to their behaviour when subjected to tensile forces $\left(F_{t}\right)$.

\subsection{Stress distribution}

To allow such a comparison, the principal stress distribution at the borehole perimeter for the model subjected to a tensile force $F_{t}=20 \mathrm{kN}$ is presented in Fig. 12 .

Contrary to the compressive loading case (Fig. 10), maximal principal compressive and tensile stresses do not appear at the same location: maximal principal tensile stresses $\left(\sigma_{t, \max }\right)$ occur at $\pm 90^{\circ}$ (perpendicular to the loading direction), where the principal compressive stresses $\left(\sigma_{c}\right)$ are zero. Similarly, the principal tensile stresses are zero at the place of maximal compressive stresses (at $\left.\pm 180^{\circ}\right)$.

Consequently, observing maximal principal tensile and minimal principal compressive stresses simultaneously at the crack origin (see below), it can be concluded that the specimens subjected to tension failed because the tensile strength was exceeded, as is usually assumed for glass structures.

Comparing now the maximal principal tensile stresses $\left(\sigma_{t, \max }\right)$ in the model subjected to a compressive or tensile load of $20 \mathrm{kN}$ the stress level in the model under tension appears to be more then double compared to what is observed in the compressive loading case (compare Figs. 10 and 12). However, the experimental investigation demonstrated that the ultimate failure load $\left(F_{u}\right)$ had almost identical values in both loading cases (Table 1 ). In other words, for the same value of the load, the principal tensile stresses for specimens under compression is only half of the tensile stresses in identical specimens under tension (Fig. 13).

In contradiction to the tensile loading case, the tensile strength of specimens subjected to compression was not exceeded when the first glass broke. Moreover, maximal tensile and compressive stresses occurred simultaneously at the crack origin. Consequently, it can be concluded that the high compressive stresses following from the compressive loading case influence the glass breakage

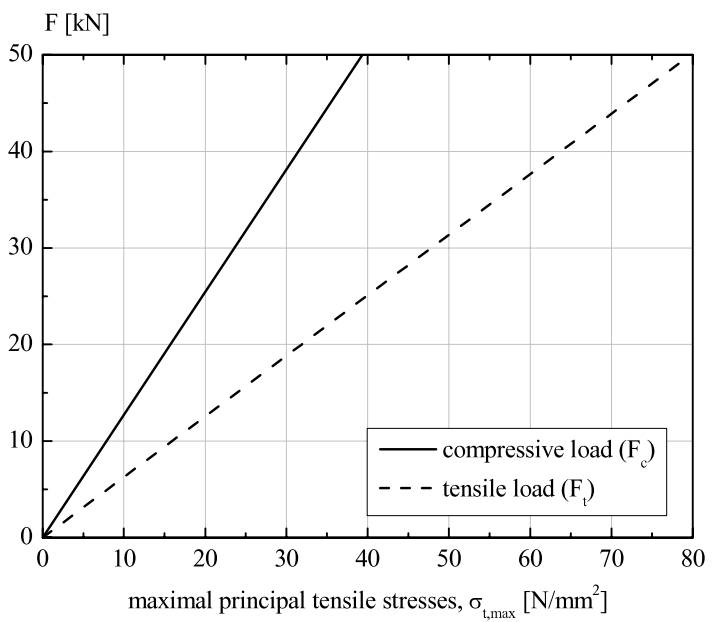

Fig. 13. Maximal principal tensile stresses as a function of the applied load: Comparison between compressive and tensile load cases. a

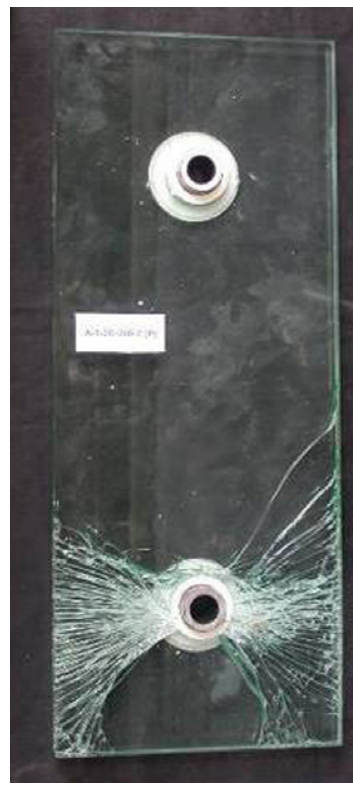

b

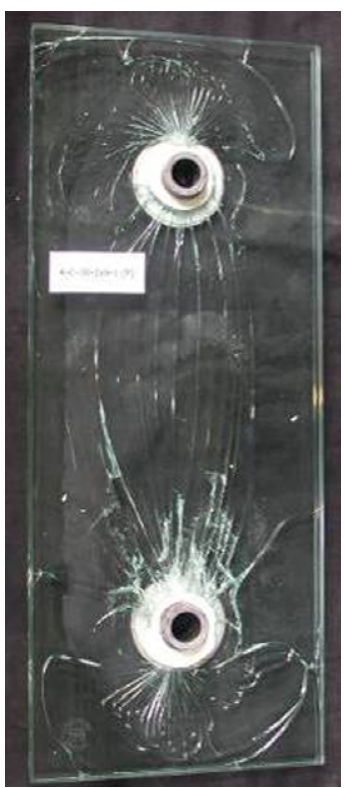

Fig. 14. Comparison of crack patterns: (a) fractures in net section due to tensile load; (b) splitting tension cracking due to compressive load.

load significantly, and that the latter does not depend only on the tensile stresses as is assumed in the classical glass failure approach. Summarising, two-dimensional stress fields which combine high tensile and high compressive stresses do have a relevant and nonnegligible impact on the resistance of the investigated in-plane compressed glass elements.

\subsection{Crack pattern}

The failure modes and fracture patterns of the specimen under tensile and compressive loads are significantly different. For both cases, crack initiations were located at the place of maximal tensile stresses, which, as explained above, occurred at different positions for each loading case.

Consequently, the failure mode for glass panels under tension was initiated by tension in the net section (Fig. 14(a)) while for glass panels under compression it was caused by splitting tension (Fig. 14(b)). 


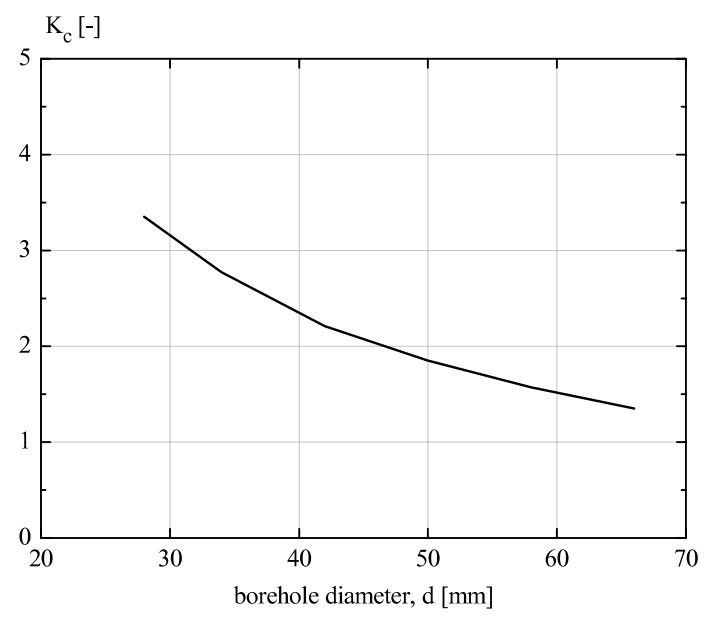

Fig. 15. Evolution of stress intensity factor $\left(K_{c}\right)$ as a function of the borehole diameter $(d)$.

\subsection{Major influencing parameters}

Analysing different parameters and their influence on the value of maximal principal tensile stresses at the contact point in glass panels subjected to a compressive load, the borehole diameter was found to have the highest impact. To measure this importance, a stress concentration factor $\left(K_{c}\right)$ is introduced:

$K_{c}=\frac{\sigma_{t, \max }}{\sigma_{\text {nom }}}$

$\sigma_{t, \max }$ : value of maximal principal tensile stress obtained by FE simulation $\left[\mathrm{N} / \mathrm{m}^{2}\right]$

$\sigma_{\text {nom }}$ : nominal stress, defined as the ratio of applied force $(F)$ to net area at the borehole $\left(\mathrm{N} / \mathrm{m}^{2}\right)$

$$
\sigma_{\text {nom }}=\frac{F}{(H-d) \cdot t}
$$

$d$ : borehole diameter.

It was found that the stress concentration factor $K_{c}$ is decreasing according to a cubic relation when the borehole diameter is increased linearly (Fig. 15). The empirical formula of the stress concentration factor as a function of the borehole diameter is derived as follows:

$K_{c}=8.85-0.3 d+0.0044 d^{2}-0.00002 d^{3}$.

On the other hand, keeping the borehole diameter $(d)$ constant and increasing the plate width $(H)$, no variation of maximal tensile stresses was found for the compressive load case.

Comparing the parametric influence on maximal tensile stresses on glass panels subjected to compressive loads with known behaviour of glass panels subjected to tensile loads $[6,8,18]$, the following differences are found:

(a) keeping the borehole diameter constant and changing the panel width has no influence on the maximal tensile stresses $\left(\sigma_{t, \max }\right)$ for glass panels subjected to compressive loads. However, it does have a significant influence on glass panels subjected to tensile loads (Fig. 16);

(b) changing the borehole diameter and keeping the panel width constant does influence the maximal tensile stresses $\left(\sigma_{t, \max }\right)$ for both compressive (Fig. 15) and tensile load cases (the net section changes);

(c) changing the borehole diameter and panel width while keeping the ratio $d / H$ constant will influence the maximal tensile stresses $\left(\sigma_{t, \max }\right)$ in the glass panel when subjected to a compressive load but not when subjected to a tensile load.

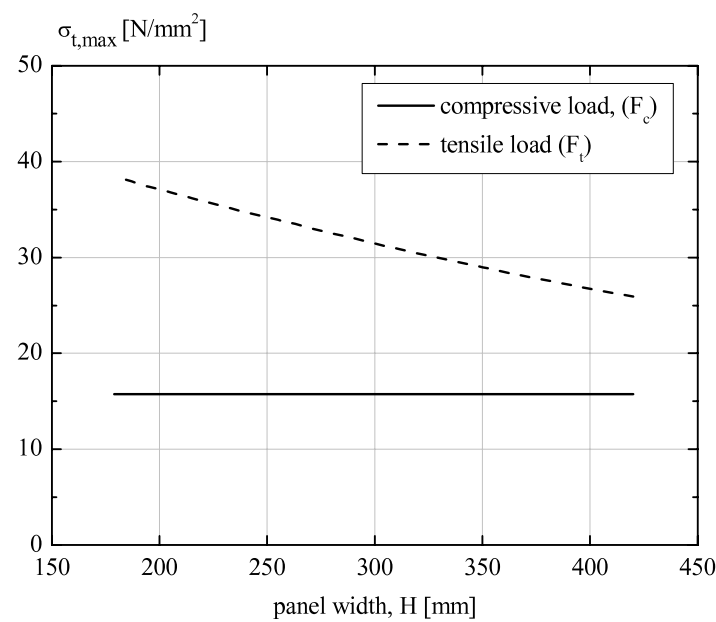

Fig. 16. Maximal tensile stresses $\left(\sigma_{t, \max }\right)$ as a function of the panel width $(H)$ for constant borehole diameter $(d=42 \mathrm{~mm})$ for a glass panel under compressive $\left(F_{c}\right)$ and tensile $\left(F_{t}\right)$ load.

\section{Conclusions}

Experimental and numerical analyses have been performed on in-plane loaded glass panels, of which the slenderness was chosen such that no buckling could occur. In this contribution, the focus was on the axial compressive loading case, which had not been investigated before. The most important conclusions are summarised below:

1. The initial compressive glass breakage load increased with the glass area, but in a non-proportional way (i.e. at a lower pace). In addition, some residual safety was available after glass breakage due to significant deformations and residual load-bearing capacity, even if the ultimate failure loads did never exceed the initial breakage loads.

2. Relatively high stress concentrations appeared at the borehole perimeter, in particular at the contact point $\left(0^{\circ}\right)$ for the compressive loading case. However, moving away from the borehole, stress values and stress peaks decreased quickly.

3. According to the loading case, cracks initiated at different locations. For the compressive loading case, initial fractures typically started at the contact point $\left(0^{\circ}\right)$ and propagated in the loading direction towards the other borehole due to splitting tension. Alternatively, cracks due to the tensile loading case initiated at $\pm 90^{\circ}$ and propagated perpendicularly to the direction of the applied load, leading to breakage of the net section on both sides of the borehole.

4. As glass is generally considered to fail due to tensile stresses (crack mode I), it is remarkable that the maximal principal tensile stress level leading to failure in the compressive loading case was less than half the value of maximal principal stresses corresponding to failure in the tensile loading case. However, further analyses demonstrated that maximal principal compressive and tensile stresses were present simultaneously at the crack origin in the compressive loading case, leading to the conclusion that the compressed specimens failed due to a complex, two-dimensional stress state and not to tensile stress alone, as is generally assumed.

5. Finally, the most important geometrical parameter (apart from the thickness) ruling the resistance of in-plane compressed glass panels, is the borehole diameter: smaller diameters lead to higher stress concentrations. However, this is not true for the tensile loading case, of which the resistance increases primarily due to an increasing panel width (and consequently, to the available net section). 


\section{Acknowledgements}

Pilkington SA $(\mathrm{CH})$, GlasTrösch SA $(\mathrm{CH})$, VIM - Verres Industriels Moutier SA $(\mathrm{CH})$ and Sadev SA (F) are gratefully acknowledged for the testing materials.

\section{References}

[1] Hertz H. Über die Berührung fester elastischer Körper und über die Härte. Z Reine Angew Math 1882;92:156-71.

[2] Persson A. On the stress distribution of cylindrical elastic bodies in contact. Göteburg: Chalmers Tekniska Hogskola; 1964.

[3] Ciavarella M, Decuzzi P. The state of stress induced by the plane frictionless cylindrical contact. I. The case of elastic similarity. Int J Solids Struct 2001;38: 4507-17.

[4] Ciavarella M, Decuzzi P. The state of stress induced by the plane frictionless cylindrical contact. II. The general case (elastic dissimilarity). Int J Solids Struct 2001;38:4225-9.

[5] Techen H. Fügetechnik für den konstruktiven Glasbau. Darmstadt: Universität Darmstadt; 1997.

[6] Overend M. The appraisal of structural glass assemblies. Surrey: University of Surrey; 2002.

[7] Siebert B. Beitrag zur Berechnung punktgelagerter gläser. München: Technische Universität München; 2004

[8] Maniatis I. Numerical and experimental investigations on the stress distribution of bolted glass connections under in-plane loads. Munich: Technische Universität München; 2006.
[9] Luible A. Stabilität von Tragelementen aus Glas. Lausanne: Ecole Polytechnique Fédérale de Lausanne; 2004.

[10] Belis J. Kipsterkte van monolithische en gelamineerde glazen liggers. Ghent: Ghent University; 2005.

[11] Belis J, Callewaert D, Delincé D, Van Impe R. Experimental failure investigation of a hybrid glass/steel beam. Eng Fail Anal 2009;16:1163-11.

[12] Kasper R. Tragverhalten von Glasträgern. Aachen: Shaker Verlag Gmbh, RWTH Aachen; 2005.

[13] Liess J. Bemessung druckbelasteter bauteile aus glas. Kassel: Books on Demand GmbH, Universität Kassel; 2001.

[14] Luible A, Crisinel M. Buckling strength of glass elements in compression. Struct Eng Int 2004;14(2):120-6.

[15] Blaauwendraad J. Buckling of laminated glass columns. Heron 2007;52(1/2): $147-64$.

[16] Englhardt O. Flächentragwerke aus Glas-Tragverhalten und Stabilität. Vienna: Universität für Bodenkultur Vienna; 2007.

[17] Blaauwendraad J. Buckling of laminated glass columns. Comparison and replacement. In: Bos F, Louter PC, Veer F, editors. Challenging glass. Amsterdam: IOS Press BV; 2008. p. 323-8.

[18] Mocibob D. Glass panels under shear loading-use of glass envelopes in building stabilization. Lausanne: Ecole Polytechnique Fédérale de Lausanne; 2008.

[19] HILTI. HIT-HY-50, Product documentation, HILTI; 2003.

[20] SAS IP, Inc. Ansys release 10. SAS IP, Inc.; 2005.

[21] HILTI. HIT-HY-70, Product documentation, HILTI; 2008. 